\title{
Effects of signaled shifts in liquid reinforcement
}

\author{
MITRI E. SHANAB, ORNA MOLAYEM, ARTHUR C. GORDON, \\ and GENE STEINHAUER \\ California State University, Fresno, California 93740
}

\begin{abstract}
The effects of introducing a discriminative stimulus at the time of shifting magnitude of liquid reinforcement were investigated in two experiments. In Experiment 1, 40 subjects received either 2 or 20 sec access to water reward, and then half of each group was shifted to the other reward magnitude. A mild tone accompanied the delivery of reward. In Experiment 2, 80 subjects received either water or sucrose reward for either 2 or $20 \mathrm{sec}$, and then half of each main group was exposed to a mild tone during delivery of the reward and the other half was not. All subjects received $20 \mathrm{sec}$ access to their respective rewards. In Experiment 1, a significant NCE was obtained, but only a graphical PCE. In Experiment 2, a significant PCE was obtained under sucrose conditions, but only a graphical PCE under water conditions.
\end{abstract}

Perhaps one of the most exasperating yet challenging phenomena in the area of learning and motivation is that of contrast. A positive contrast effect (PCE) is said to have taken place when subjects shifted from a small to a larger reward in the runway run significantly faster than control subjects receiving the larger reward all the time. Conversely, if subjects shifted from a large to a smaller reward run significantly slower than control subjects receiving the smaller reward all the time, a negative contrast effect (NCE) is said to have occurred.

It has been virtually impossible to obtain PCE based on simple upward shifts in the magnitude of food, sucrose, or water reward (Cox, 1975; Flaherty, Riley, \& Spear, 1973; Spencer \& Shanab, 1979). On the other hand, while NCE has been consistently obtained based on simple downshifts in food reward in the runway (Cox, 1975), similar simple shifts in either water reward (Spencer \& Shanab, 1979) or sucrose reward (Barnes \& Tombaugh, 1973; Ison \& Rosen, 1968) have failed to produce reliable NCE.

These inconsistencies become more frustrating when contrast effects based on different instrumental responses are compared. Although positive contrast is very difficult to obtain in the runway, as noted earlier, its counterpart is readily obtained in the Skinner box, especially when pigeons are used (Schwartz \& Gamzu, 1977). Typically, when the schedule associated with one component of a multiple schedule (varied component) is decreased while the schedule associated with the other component (constant component) remains unchanged, the response rate in the constant component increases in a direction opposite to that in the varied component. This phenomenon is called positive behavioral contrast (PBC). On the other hand, while negative contrast is consistently obtained when downshifts in solid-food reward are made in the runway, it does not appear to be as reliable an effect in the Skinner box (Schwartz \& Gamzu, 1977; Terrace, 1966). Negative behavioral contrast (NBC) occurs when responding in the constant component decreases while responding in the varied component increases following a shift to a denser schedule.

The main purpose of the present series of investigations was to study contrast effects in the runway based on shifts in liquid reinforcement when such shifts are accompanied by a discriminative stimulus. It is clear that there are a lot of differences in both procedure and design that might account for the inconsistency in results between the runway and Skinner box studies. However, the two differ in one distinct way. Unlike the magnitude shifts in the runway, the schedule shifts in the Skinner box are associated with discriminative stimuli. Thus, it could be argued that the stimulus, $\mathrm{S}+$, associated with the constant component of the multiple schedule in behavioral constrast studies serves as a differential predictor of the shift in reinforcement schedule. This is essentially the reasoning underlying the additivity theory (cf. Schwartz \& Gamzu, 1977). According to this theory, PBC occurs when the S+ becomes differentially or, more specifically, classically conditioned to the reinforcer. Thus, when the $S-$ of the varied component signals extinction, responding in the presence of $\mathrm{S}+$ is controlled not only by the already established response-reinforcer operant contingency, but also by the newly developed classically conditioned stimulus-reinforcer contingency. In other words, the observed increase in response rate reflects the summation of the rates of the previously operantly conditioned pecks and the newly formed classically conditioned pecks.

It should be noted that many years ago, Spence (1956), partly in response to the anomalous results of the early contrast studies carried out by Crespi (1942) and Zeaman (1949), developed an incentive motivational theory of instrumental learning in which he proposed that subjects not only learn to make instrumental responses but also learn to make classically conditioned responses in anticipation of the reinforcer itself. Spence proposed that classical conditioning was an inherent 
part of instrumental learning, for the classically conditioned anticipatory responses determine the strength and direction of the instrumental response. Specifically, Spence suggested that the subject learns to make conditioned goal responses $\left(\mathrm{r}_{\mathrm{g}}\right)$ in the goal area that, through backward generalization, are evoked at the start. The $r_{g}$ responses produce their own interoceptive stimuli, which become conditioned to the instrumental response. The $r_{g}-s_{g}$ mechanism is conceived as serving a dual function, an associative as well as a motivational one. The stimuli in the alley evoke the $r_{g}-s_{g}$ mechanism, which not only triggers and directs the behavior of the subject but also determines the strength of the response.

Spence (1956) proposed that the $\mathrm{r}_{\mathrm{g}}-\mathrm{s}_{\mathrm{g}}$ was the underlying mechanism for the incentive motivation construct $(\mathrm{K})$ that combined multiplicatively with habit strength $(\mathrm{H})$ and additively with drive (D) to determine reaction potential (E). This line of theorizing would provide an adequate explanation of PCE if it could be assumed that magnitude of reward exerts a relative rather than an absolute effect on behavior, or, in Spence's terms, if it could be assumed that the old $\mathrm{K}$ associated with the runway stimuli and the new $K$ associated with the discriminative stimulus that signals the shift in reward magnitude combine together in such a manner as to produce another $\mathrm{K}$ that exceeds the $\mathrm{K}$ value of the control group. Thus, both additivity theory and Spence's theory can predict that a stimulus correlated with the shift in reinforcement will enhance responding and possibly lead to contrast. The following two studies were designed to test this prediction.

\section{EXPERIMENT 1}

\section{Method}

Design. The experiment consisted of two phases. In Phase 1, two groups of rats were given access to water for either 2 sec (S) or $20 \mathrm{sec}$ (L). In Phase 2, each main group was divided in half, with one subgroup in each main group continuing to receive the same reward as before and the second being shifted to the other reward condition. This resulted in a 2 by 2 factorial design, yielding the following four groups: LL, SS, LS, and SL, with each letter denoting the magnitude of reward received in each phase. A mild tone accompanied the delivery of the reward in Phase 2.

Subjects. The subjects were 48 naive male albino rats of the Sprague-Dawley strain, about 90 days old at the beginning of the experiment.

Apparatus. A $1.5-\mathrm{m}$ runway made of unpainted redwood was used. The runway was covered with Plexiglas and was $23 \mathrm{~cm}$ high and $10 \mathrm{~cm}$ wide throughout. The startbox was $18 \mathrm{~cm}$ long and $17 \mathrm{~cm}$ wide, and the goalbox was $30.5 \mathrm{~cm}$ long and $12 \mathrm{~cm}$ wide. The startbox and goalbox were each separated from the run section by guillotine doors. In the goalbox, a small metal plate $(2.5 \times 2.5 \mathrm{~cm})$ was fixed to the far wall and surrounded an aperture located $4.2 \mathrm{~cm}$ from the floor. Through this aperture, a drinking tube was presented to the subject automatically and retracted immediately following the prescribed access interval. Four sets of photocells were installed in the runway. Interruption of any of the four photobeams started and/or stopped any one of the three Standard Electric timers that measured start, run, and goal times. The first through fourth photocells were located $6.4,21.5,103$, and $115 \mathrm{~cm}$ from the startbox, respectively.
Procedure. Upon arrival from the supplier, the subjects were housed in individual cages with free access to food and water and were handled daily for $2 \mathrm{~min} /$ day for 15 days. Subjects were then placed on a 23.75 -h water-deprivation schedule. At least $30 \mathrm{~min}$ after handling each day, the subjects were given water access for $15 \mathrm{~min}$. After a total of 11 days on the deprivation schedule, the subjects were given exploration in the runway. No water was provided in the runway during exploration. On the first 2 days, each subject was given $90 \mathrm{sec}$ exploration of the runway with the guillotine doors open and all equipment turned off. On the 3 rd and 4 th days, the doors were operated in the same fashion as on regular trials and the equipment was turned on to accustom the subjects to its sounds. Furthermore, 4 days of operant levels were taken by measuring the time taken by each subject to traverse the entire runway on the first run. On each of these days, the subjects were given either 2 or $20 \mathrm{sec}$ access to water in the goalbox $30 \mathrm{~min}$ after the completion of their trial run, in order to familiarize them with the water tube. The subjects were then assigned to two main groups, and Phase 1 was started. On the first 2 days of this phase, each subject received 1 trial/day, but 2 trials/day thereafter. On each trial, the subject was placed in the startbox and, as soon as it oriented toward the run section, both guillotine doors were opened. Interruption of the last photobeam provided each subject with access to the drinking tube for either 2 or $20 \mathrm{sec}$. If a subject failed to pass through a section of the runway in $60 \mathrm{sec}$, a time of $60 \mathrm{sec}$ was recorded for that and subsequent sections of the runway. Trials were massed, with an intertrial interval of approximately $10 \mathrm{sec}$. Phase 1 lasted 18 days. In Phase 2, the subjects were matched on the basis of their asymptotic performance levels in Phase 1, and a random half of each.main group was shifted to the opposite reward magnitude. Duration of access to the drinking tube was again either 2 or $20 \mathrm{sec}$. Phase 2 was continued for 13 days at 2 trials/day. In Phase 2 , a mild tone $(71 \mathrm{~dB})$ was turned on $1 \mathrm{sec}$ before the delivery of the drinking tube and was turned off when the tube was retracted either 2 or $20 \mathrm{sec}$ later. During both phases, each subject received its 15 -min daily ration of water at least 30 min following its second daily trial.

\section{Results}

Although all speed measures were similar, the goal speeds were more pronounced and will thus be reported here. The results of a $t$ test over the last three blocks of Phase 1 showed that the two groups did not differ significantly from each other $[t(46)=1.25, p>.05]$.

As Figure 1 shows, the performance of the downshifted group (LS) was depressed relative to its control group (SS) throughout the shift phase. This was supported by the results of an analysis of variance performed over Blocks 1-10. Relative to the nonshifted controls, the subjects shifted to small reward displayed a significant $\mathrm{NCE}[\mathrm{F}(1,44)=4.19, \mathrm{p}<.05]$.

A similar analysis over Blocks 1-13 yielded a marginally significant $\operatorname{NCE}[F(1,44)=3.96, p>.05]$. It should be noted that the graphical NCE that appears over Block 1 was not significant $[F(1,44)=1.78$, $p>.05]$. The results of similar analyses performed to test for positive contrast yielded nonsignificant $F$ values (all Fs $<1$ ).

\section{EXPERIMENT 2}

\section{Method}

Design. The experiment was divided into two phases. In 


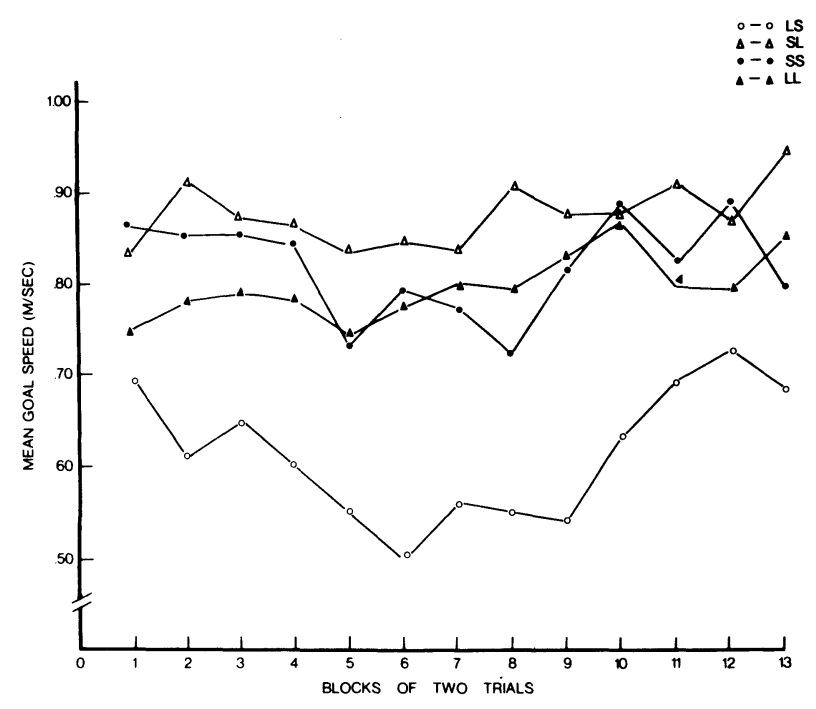

Figure 1. Mean goal speed as a function of an upward or downward shift in water reward.

Phase 1, 80 subjects were randomly assigned to four reward conditions: access to water for either $2 \mathrm{sec}$ or $20 \mathrm{sec}$ and access to sucrose for either $2 \mathrm{sec}$ or $20 \mathrm{sec}$. In Phase 2, each group was further divided in half and received $20 \mathrm{sec}$ access to the same reward. A tone was presented in the goalbox to four subgroups. This resulted in a 2 by 2 by 2 factorial design yielding eight groups of 10 subjects/group.

Subjects. The subjects were 80 naive male albino rats of the Sprague-Dawley strain, approximately 90 days old at the beginning of the experiment.

Apparatus. The runway used was the same as the one used in Experiment 1.

Procedure. Upon arrival from the supplier, the rats were placed in individual cages with free access to food and water. After a 2-day rest period, the subjects were handled daily for a period of 14 days. Subjects were then placed on a $23.75-\mathrm{h}$ water-deprivation schedule. The subjects did not receive their $15 \mathrm{~min}$ access to water until at least $20 \mathrm{~min}$ had elapsed after handling. The subjects were kept on the deprivation schedule for 10 days before they were allowed access to the runway. The subjects were then given $90-\mathrm{sec}$ exploration periods of the runway for 2 days. On the 1 st day, the subjects were given free exploration with all the equipment turned off and the guillotine doors open. On the 2 nd day, all the equipment was operated normally to accustom the subjects to the procedures and sounds. Following the exploration period, the subjects were run through the maze on 3 consecutive days to measure their operant levels. On each of these 3 days, the subjects were given access to water in the goalbox to familiarize them with the drinking tube. The access time was $5 \mathrm{sec}$ the $1 \mathrm{st}$ day, $10 \mathrm{sec}$ the $2 \mathrm{nd}$ day, and $15 \mathrm{sec}$ the 3rd day. In all cases, the subjects were placed in the goalbox at least $30 \mathrm{~min}$ after they had been removed from the apparatus. The subjects were then assigned randomly to four groups, and Phase 1 was started. Each subject was given 2 trials/day. A typical trial consisted of placing each subject in the startbox, and as soon as it oriented toward the runway, the guillotine doors were opened. Interruption of the last photobeam provided each rat with access to the drinking tube, which contained either water or sucrose, for either $2 \mathrm{sec}$ or $20 \mathrm{sec}$. If a subject failed to pass through any section of the runway in $30 \mathrm{sec}$, a time of $30 \mathrm{sec}$ was recorded and the subject was guided into the next section of the runway. Trials were massed, with an interval between trials of approximately $20 \mathrm{sec}$. Phase 1 lasted 20 days.

In Phase 2, all subjects were given 20 sec access to the drinking tube. Each group was split into two subgroups, matched on the basis of the total time averaged over the last five blocks of Phase 1. The additional variable of tone was then randomly assigned to one of the two subgroups in each of the four main groups. A mild tone $(71 \mathrm{~dB})$ was presented in the goalbox along with delivery of the reward. Phase 2 lasted 10 days. The sucrose solution used in both phases was mixed daily and consisted of $18 \mathrm{~g}$ of commercial sugar mixed with $100 \mathrm{~g}$ of tap water. In both phases, the subjects had free access to food and received their $15-\mathrm{min}$ daily ration of water at least $30 \mathrm{~min}$ after completion of their second daily trial.

\section{Results}

All analyses are based on speed measures. Since all measures were highly similar, only the analysis of total speed will be reported here.

A two-way analysis of variance performed over the last three blocks of Phase 1 yielded nonsignificant main effects due to magnitude $(F<1)$ and type of reward $[F(1,76)=2.91, p>.05]$. The interaction of magnitude and reward type was also not significant $[F(1,76)=3.01, p>.05]$.

As Figure 2 shows, the upshifted groups in the sucrose condition ran faster than their controls. This appears to be true regardless of whether or not the tone was presented to the upshifted subjects in the goal area. On the other hand, it appears that in the water condition, only those shifted in the presence of tone ran faster than their controls. The results of a three-way analysis of variance over the entire blocks in Phase 2 support in general the graphical analysis in showing that only the main effect of magnitude shift $[F(1,72)=$ $10.60, p<.002]$ and the interaction of shift and type of reward $[F(1,72)=7.61, p<.01]$ were significant. Tests of simple effects (ignoring the tone variable) yielded a highly significant PCE $[F(1,72)=18.08, p<.01]$ based on upshifts in sucrose reward, but a nonsignificant PCE $[F(1,72)<1]$ based on upward shifts in water reward.

\section{GENERAL DISCUSSION}

The results of Experiment 1 provide partial support for the hypothesis that the introduction of a discriminative stimulus at the time of the shift in reinforcement conditions would enhance the emergence of contrast. Indeed, when a tone accompanied the downshift in water reward, a significant NCE was observed. The presence of NCE in Experiment 1 represents the first reported evidence of contrast based on simple shifts in magnitude of undelayed water reward. It will be recalled that Sgro and Weinstock (1963) reported obtaining a significant PCE based on shift from 15-secdelay to immediate-reward conditions. It should be noted that Sgro and Weinstock did not shift magnitude of reward. Moreover, the contrast obtained was based on a restricted sample. Later attempts to obtain NCE based on shifts in delay of water reward have failed to obtain negative contrast (Ferrell \& Shanab, 1975; Spencer \& Shanab, 1979).

The appearance of NCE in Experiment 1 cannot be unequivocally attributed to the presence of tone, since the design did not include appropriate control groups that did not receive the tone at the time of the shift. These controls were omitted primarily because it was reasoned that a sufficient number of studies were run in our laboratories, and, apparently, elsewhere, that were consistent in showing a lack of contrast effects based on shifts of undelayed reward. Although the upshifted group appears to have run faster than its control throughout the shift phase, the difference was not statistically significant. The use of conventional 


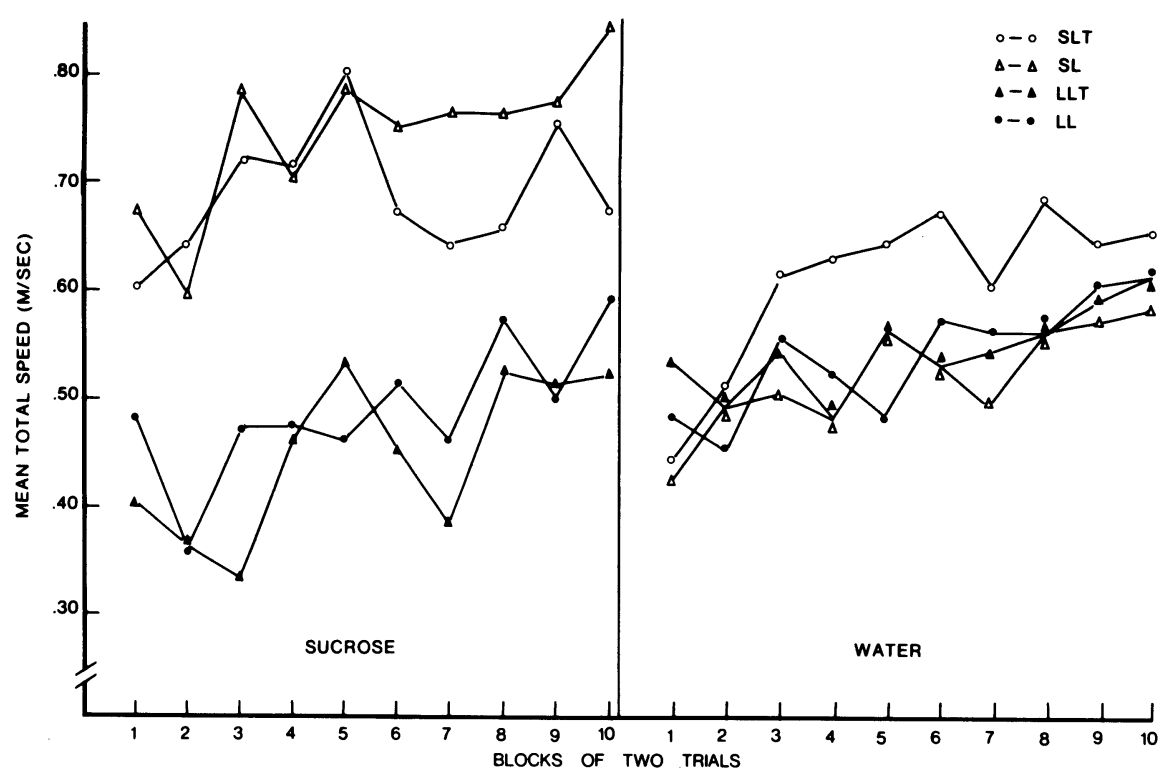

Figure 2. Mean total speed as a function of an upward shift in either sucrose or water reward when the shift was or was not accompanied by a tone.

groups that are shifted in the absence of a discriminative stimulus would have made it possible to determine whether or not this graphical PCE could be attributed to the presence of tone. When such groups were included in Experiment 2, a graphical, albeit nonsignificant, PCE was observed only with tone. The persistence of the graphical PCE suggests that the weak effect observed is probably due to procedural considerations.

The strong PCE observed in the sucrose condition in Experiment 2 is perplexing. On one hand, the PCE is not consistent with the findings of previous studies that failed to obtain such an effect (Flaherty et al., 1973; Goodrich, 1962; Goodrich \& Zaretsky, 1962; Shanab, Domino, \& Melrose, 1977; Spear, 1965). On the other hand, the significant PCE obtained regardless of the tone condition does not support the hypothesis tested. The tone seems to have had more of an effect on water shifts. In view of the persistence of the graphical PCE based on water shifts in the presence of tone, it is conceivable that a Type II error was committed as far as the effect of tone is concerned.

Although the results of both experiments provide in general partial support for Spence's (1956) theory, as well as for additivity theory, it is clear that further investigations of the effect of the discriminative stimulus on contrast in both operant and instrumental conditioning situations need to be carried out to enhance our understanding of this puzzling phenomenon.

\section{REFERENCES}

Barnes, W., \& Tombaugh, T. N. Another failure to obtain negative incentive contrast reductions in sucrose reward. Psychological Reports, 1973, 33, 801-802.

Cox, W. M. A review of recent incentive contrast studies involving discrete-trial procedures. Psychological Record, 1975, 25, 373-393.

Crespi, L. P. Quantitative variations of incentive and performance in the white rat. American Journal of Psychology, 1942, 55, 467-517.

Ferrell, H. J., \& Shanab, M. E. Contrast effects as a function of shifts in delay of water reward. Bulletin of the Psychonomic Society, 1975, 5, 417-420.
Flaherty, C. F., Riley, E. P., \& Spear, N. E. Effects of sucrose concentration and goal units on running behavior in the rat. Learning and Motivation, 1973, 4, 163-175.

Goodrich, K. P. Supplementary report: Running speed as a function of sucrose concentration in a prior free-drinking period. Psychological Reports, 1962, 11, 528-530.

Goodrich, K. P., \& ZARetsky, H. Running speed as a function of concentration of sucrose during pre-training. Psychological Reports, 1962, 11, 463-468.

Ison, J. R., \& Rosen, A. J. Extinction and reacquisition performance as a function of sucrose-solution rewards and number of acquisition trials. Psychological Reports, 1968, 22, 375-379.

Schwartz, B., \& Gamzu, E. Pavlovian control of operant behavior: An analysis of autoshaping and its implications for operant conditioning. In W. K. Honig \& J. E. R. Staddon (Eds.), Handbook of operant behavior. Englewood Cliffs, N.J: Prentice-Hall, 1977.

Saro, J. A., \& Weinstock, S. Effects of delay on subsequent running under immediate reinforcement. Journal of Experimental Psychology, 1963, 66, 260-263.

Shanab, M. E., Domino, J., \& Melrose, S. The effects of shifts in delay of liquid sucrose reward in thirsty rats. Bulletin of the Psychonomic Society, 1977, 10, 287-290.

SPEAR, N. E. Replicative report: Absence of a successive contrast effect on instrumental running behavior after a shift in sucrose concentration. Psychological Reports, 1965, 16, 393-394.

SPENCE, K. W. Behavior theory and conditioning. New Haven, Conn: Yale University Press, 1956.

Spencer, R. E., \& Shanab, M. E. Contrast effects as a function of delay and shifts in magnitude of water reward in thirsty rats. Bulletin of the Psychonomic Society, 1979, 13, 93-96.

Terrace, H. S. Stimulus control. In W. K. Honig (Ed.), Operant behavior: Areas of research and application. New York: Appleton-Century-Crofts, 1966.

ZEAMAN, D. Response latency as a function of the amount of reinforcement. Journal of Experimental Psychology, 1949, 39, 466-483.

(Received for publication August 24, 1981.) 